\title{
Protocolo para captação, transporte e preservação de tecido osteocondral humano*
}

\section{Protocol for Harvest, Transport and Storage of Human Osteochondral Tissue}

\author{
Thiago Alberto Vivacqua ${ }^{1}$ Rafael Dantas Prinz ${ }^{1}$ Naasson Cavanellas $^{1}$ João Maurício Barretto ${ }^{1}$ \\ Eduardo Branco de Sousa ${ }^{1}$ Diego Pinheiro Aguiar ${ }^{1}$
}

${ }^{1}$ Divisão de Pesquisa, Instituto Nacional de Traumatologia e Ortopedia Jamil Haddad, Rio de Janeiro, RJ, Brasil

Endereço para correspondência Thiago Vivacqua, MD, Instituto Nacional de Traumatologia e Ortopedia Jamil Haddad, Av. Avenida Brasil 500, Rio de Janeiro, RJ, Brasil (e-mail: drthiagovivacqua@gmail.com).

Rev Bras Ortop 2020;55(2):163-169.

\section{Resumo}

\section{Palavras-chave}

- cartilagem articular

- aloenxerto

- transplante ósseo

- coleta de tecidos e órgãos

- lesão osteocondral
Objetivo Elaborar um protocolo para a captação, transporte e preservação de tecido osteocondral humano para utilização em banco de tecidos (BT).

Métodos Foram analisados fragmentos osteocondrais com dimensão de $2 \mathrm{~cm}^{3}$ de 5 doadores cadáveres com idades entre 15 e 45 anos. As amostras foram armazenadas em meio de preservação celular contendo: albumina humana, Iscove's e vancomicina preservados à temperatura de $4^{\circ} \mathrm{C}$. A concentração de proteoglicanos no meio extracelular foi quantificada pelo uso de Safranina-O, enquanto a análise estrutural do tecido foi avaliada através de estudo histológico com lâminas coradas em hematoxilina-eosina. As imagens obtidas foram analisadas segundo os escore histológicos de Mankin e o escore proposto pela OsteoArthritis Research Society International. As amostras foram analisadas com $0,15,30$ e 45 dias de preservação.

Resultados Os fragmentos osteocondrais estudados apresentaram diminuição progressiva na concentração de proteoglicanos com o aumento do tempo de preservação. Após 30 dias de preservação, foram identificadas alterações estruturais com descontinuidade da camada superficial da cartilagem. Segundo os resultados obtidos pelo escore de Mankin, houve diferença com significância estatística entre 15 e 30 dias de preservação do tecido.

Conclusão O protocolo descrito definiu o transporte de joelho em bloco imerso em Ringer Lactato em temperatura controlada a $10^{\circ} \mathrm{C}$ até sua chegada ao BT. Após o processamento, a solução de preservação foi composta por meio de cultura celular sem soro Iscove's suplementado com albumina humana a $10 \%$ e vancomicina $100 \mu \mathrm{g} / \mathrm{mL}$. $O$ tecido foi preservado à temperatura de $4^{\circ} \mathrm{C}$ até o momento do transplante caracterizando a preservação a fresco.

Trabalho desenvolvido no Instituto Nacional de Traumatologia e Ortopedia Jamil Haddad, Rio de Janeiro, RJ, Brasil.

recebido

27 de Agosto de 2018

Aceito

22 de Janeiro de 2019
DOI https://doi.org/

10.1055/s-0039-3400522. ISSN 0102-3616.
Copyright $\odot 2020$ by Sociedade Brasileira License terms de Ortopedia e Traumatologia. Published by Thieme Revinter Publicações Ltda, Rio de Janeiro, Brazil 


\author{
Abstract \\ Keywords \\ - cartilage, articular \\ - allografts \\ - bone \\ transplantation \\ - tissue and organ \\ harvesting \\ - osteochondral \\ lesion
}

Objective To elaborate a protocol for the harvest, transport, and preservation of human osteochondral tissue for use in tissue banks (TBs).

Methods Osteochondral fragments measuring $2 \mathrm{~cm}^{3}$ of 5 cadaveric donors aged between 15 and 45 years old were analyzed. The samples were stored in cell preservation medium containing: human albumin, Iscove's and vancomycin preserved at $4^{\circ} \mathrm{C}$. The concentration of proteoglycans in the extracellular medium was quantified by the use of Safranin-O, while tissue structural analysis was assessed by histological study with hematoxylin-eosin stained slides. The images obtained were analyzed according to the histological scores of Mankin and the score proposed by the OsteoArthritis Research Society International. The samples were analyzed with $0,15,30$ and 45 days of preservation.

Results The osteochondral fragments studied showed a progressive decrease in proteoglycan concentration with increased preservation time. After 30 days of preservation, structural changes were identified with discontinuity of the cartilage surface layer. According to the results obtained by the Mankin score, there was a statistically significant difference between 15 and 30 days of tissue preservation.

Conclusion The protocol described defined knee transport immersed in Lactated Ringer at a controlled temperature of $10^{\circ} \mathrm{C}$ until its arrival at the TB. After processing, the preservation solution was composed of Iscove's serum-free cell culture medium supplemented with $10 \%$ human albumin and $100 \mu \mathrm{g} / \mathrm{ml}$ vancomycin. The tissue was preserved at a temperature of $4^{\circ}$ $\mathrm{C}$ until the moment of transplantation characterizing the fresh preservation.

\section{Introdução}

O transplante osteocondral alógeno (TOA) representa a única opção de tratamento capaz de repor o estoque ósseo e restaurar a superfície articular com cartilagem hialina após lesões profundas nas articulações sinoviais. ${ }^{1,2}$ A principal indicação para o TOA é a presença de lesão osteocondral focal $>2,0 \mathrm{~cm}^{2}$ associada a sintomas álgicos nas articulações de carga. ${ }^{1-4}$ A preservação do tecido osteocondral humano representa um fator chave no sucesso do TOA. O tempo de armazenamento do tecido, assim como os meios de preservação utilizados, estão relacionados à manutenção da viabilidade dos condrócitos após o procedimento. ${ }^{1,5}$

A temperatura de $4^{\circ} \mathrm{C}$ é a mais utilizada na preservação de tecido osteocondral em humanos ou modelos animais. ${ }^{6} \mathrm{O}$ resfriamento tecidual abaixo da temperatura corpórea média de $37^{\circ} \mathrm{C}$ induz à redução do metabolismo celular dos condrócitos, levando ao menor consumo dos nutrientes fornecidos pelo meio de preservação utilizado. ${ }^{7}$ Até hoje, ainda não há consenso na literatura quanto à padronização de um protocolo para captação, transporte e preservação do tecido osteocondral tanto nos bancos de tecidos (BTs) nacionais quanto naqueles localizados em outros países do continente americano e europeu. $O$ objetivo do presente estudo foi elaborar um protocolo para a captação, transporte e preservação de tecido osteocondral humano para utilização em BT.

\section{Material e Métodos}

\section{Seleção dos Doadores}

A população do estudo foi composta por 5 doadores cadáveres (DCs) de tecido musculoesquelético no período de junho de
2015 a dezembro de 2016 e que preenchiam os critérios para doação de órgãos ao Sistema Nacional de Transplantes (SNT), de acordo com a normativa publicada pelo Ministério da Saúde (MS) Portaria $\mathrm{n}^{\circ} 2.600$ publicada em 21 de outubro de 2009. Após aprovação pelo Comitê de Ética em Pesquisa institucional (CAAE 45288015.7.0000.5273), foram incluídos no estudo os DCs com idades entre 15 e 45 anos sem história de trauma, cirurgia ou infecção prévia na articulação do joelho selecionada para captação e retirada dos fragmentos osteocondrais. A articulação captada foi removida íntegra e levada para o BT, onde foi processada e submetida à avaliação visual, sendo excluída no caso de apresentar qualquer lesão na cartilagem articular. Também foram excluídos os DC oriundos de fora do estado do Rio de Janeiro devido ao tempo prolongado de deslocamento entre o local de captação e a sede do banco. Por fim, foram selecionados os joelhos de cinco DCs para a realização da pesquisa (- Figura $\mathbf{1}$ ).

\section{Protocolo de Captação e Transporte}

Após incisão mediana no joelho e dissecção subcutânea, foram realizadas osteotomias femorais $2,0 \mathrm{~cm}$ acima do polo superior da patela e tibial, $5 \mathrm{~cm}$ distal ao tubérculo tibial, com auxílio de serra oscilatória, sem abertura da cápsula da articulação do joelho. A articulação foi imersa em Ringer Lactato, embalada a vácuo e armazenada em frasqueira térmica na temperatura de $4^{\circ} \mathrm{C}$, controlada por termostato local até a chegada no BT (-Figura 2).

\section{Protocolo de Processamento do Tecido Osteocondral Humano}

O processamento do tecido foi realizado por um médico membro da equipe de pesquisa em sala classificada como ISO 


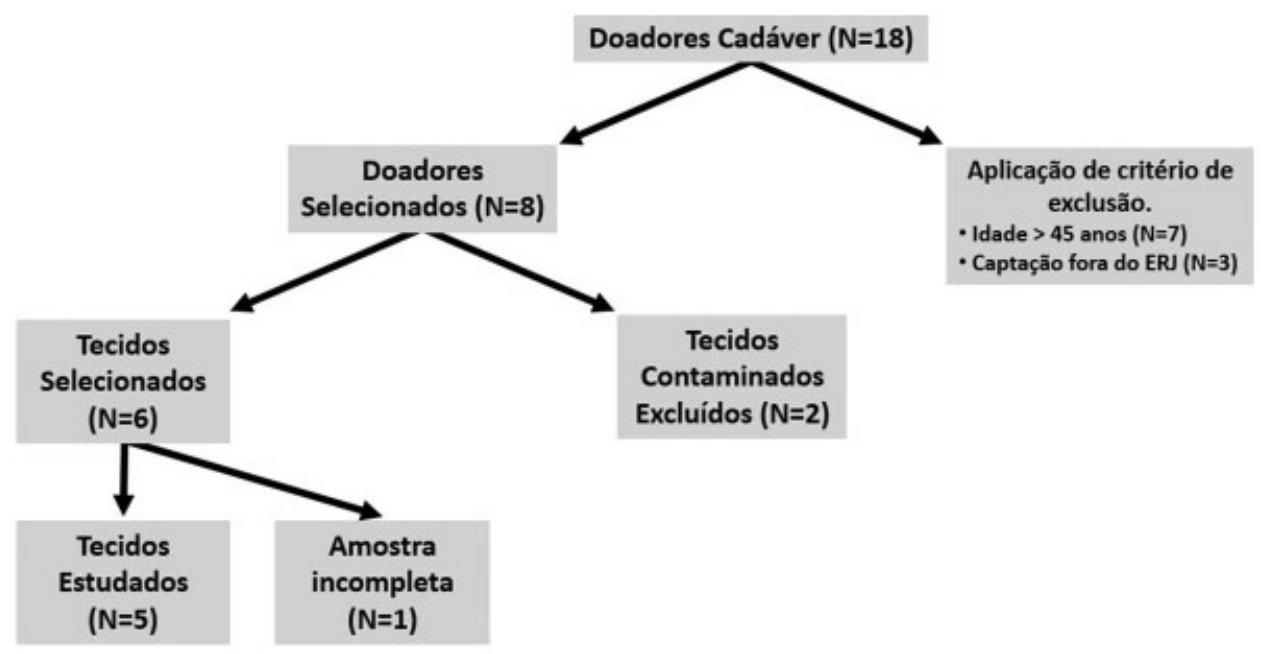

Fig. 1 Fluxograma de seleção dos doadores cadáver para pesquisa. DC (doador cadáver).

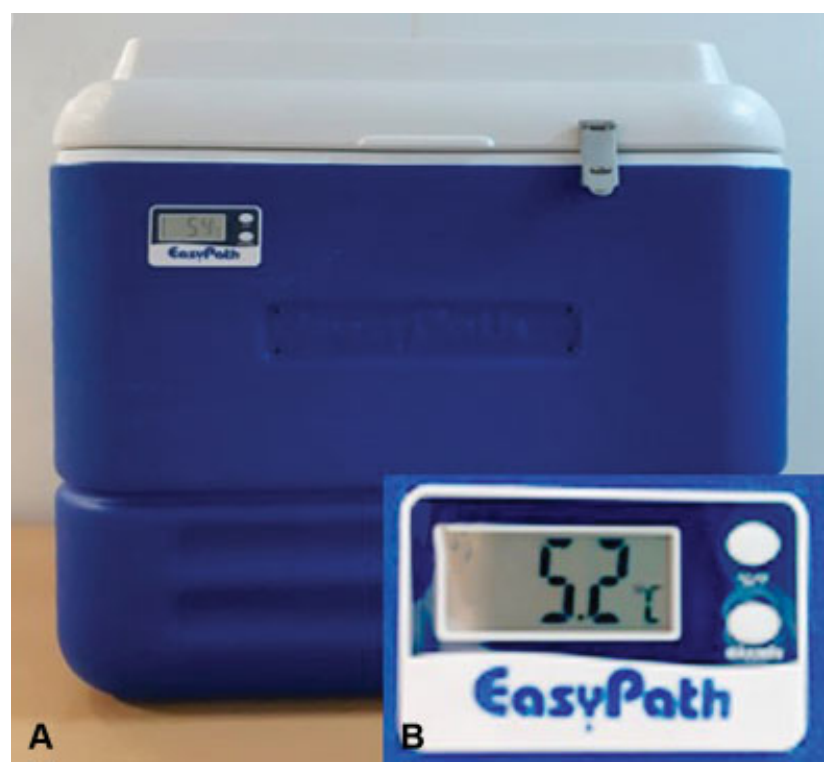

Fig. 2 Equipamentos de transporte do tecido osteocondral. Frasqueira térmica para transporte de tecido osteocondral (A). Termômetro para controle de temperatura (B). Fonte: Arquivo pessoal.

5 localizada dentro do BT. Foram coletados 8 fragmentos com $2 \times 3 \mathrm{~cm}^{2}$ por DC para análise histológica, que foram preservados a $4^{\circ} \mathrm{C}$. O meio de preservação utilizado foi composto pelo meio de cultura celular sem soro Iscove's (Thermo Fischer, Waltham, MA, EUA) suplementado com albumina humana a $10 \%$ e vancomicina $100 \mu \mathrm{g} / \mathrm{mL}$. Os tecidos foram submetidos à análise no dia da captação, definido como dia zero (d0) e após 15 (d15), 30 (d30) e 45 (d45) dias de preservação ( - Figura 3). Também foram enviados fragmentos de tecido para cultura no laboratório de microbiologia da instituição para excluir infecção.

\section{Protocolo de Análise Tecidual}

Os fragmentos osteocondrais foram submetidos a cortes histológicos e corados pela técnica de hematoxilina e eosina (H\&E), para análise global do tecido, e com Safranina O (SO), para avaliação quanto à deposição de glicosaminoglicanos. As lâmi-
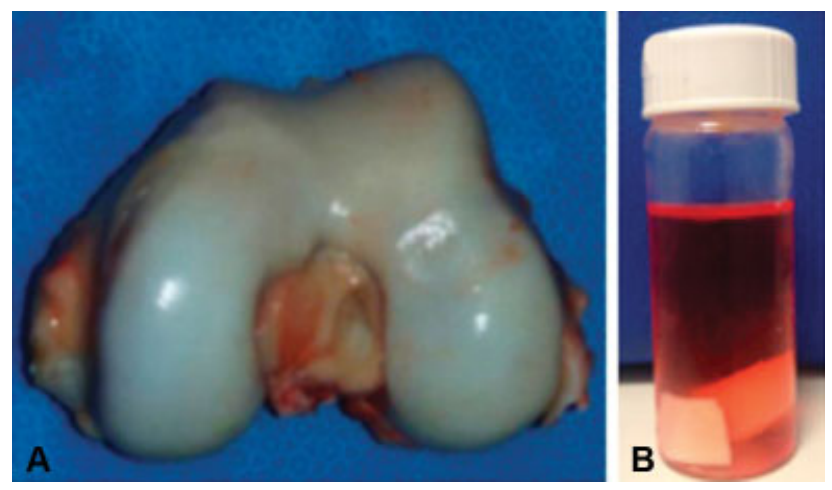

Fig. 3 Metodologia de preparo dos fragmentos osteocondrais para análise tecidual. Superfície articular do fêmur distal selecionada para a retirada de $\mathrm{FO}$ para análise histológica (A). Os fragmentos foram mantidos no meio de preservação e mantidos a $4^{\circ} \mathrm{C}$ (B). Período de avaliação de amostra (C). D (dia). Fonte: Arquivo pessoal.

nas foram analisadas ao microscópio ótico e fotografadas para registro dos resultados em aumento de 100x. As imagens geradas foram nomeadas alfanumericamente, de modo que a letra indicava o tempo de preservação do tecido e o número indicava o doador, para que os avaliadores fossem cegados quanto ao tempo de preservação e ao DC. Os avaliadores receberam as imagens obtidas em um dispositivo de armazenamento eletrônico e os formulários para aplicação dos dois escores selecionados para a pesquisa. Foram utilizados o escore de Mankin modificado, ${ }^{8}$ cuja pontuação obtida varia de 0 a 14 pontos, e o escore descrito pela OsteoArthritis Research Society International (OARSI $)^{9}$ que quantifica as alterações relacionadas à degeneração da cartilagem sinovial, graduando de 0 a 6 .

\section{Análise dos Resultados}

Os resultados obtidos foram tabulados em planilha Microsoft Excel (Microsoft Corporation, Redmond, WA, EUA) para posterior análise estatística. A análise do presente estudo foi formada pelas pontuações obtidas a partir da avaliação visual dos fragmentos osteocondrais nos 4 momentos de avaliação (d0, d15, d30, d45) segundo os dois escores selecionados previamente. Ao todo, foram realizadas 38 avaliações, que compõem a 
dimensão do banco de dados do presente estudo. Houve a perda de uma avaliação referente ao DC 388 no tempo d0. Os dados coletados foram analisados pelo programa IBM SPSS Statistics for Windows, Versão 22.0 (IBM Corp. Armonk, NY, EUA). Os gráficos foram construídos no programa Microsoft Excel 2011.

Para caracterização da amostra e análise descritiva das variáveis, dada a natureza qualitativa dos escores, a média e as estatísticas baseadas na média não puderam ser calculadas, por isso os dados foram sintetizados por meio de distribuições de frequências relativas e da estatística descritiva como mediana, mínimo e máximo. Seguindo a abordagem não paramétrica de análise, dada a natureza qualitativa ordinal dos escores, a significância da evolução temporal de um escore foi avaliada pelo teste de Wilcoxon, comparando pareadamente os escores de uma avaliação com os respectivos escores da avaliação anterior. Todas as comparações foram realizadas considerando nível de significância máximo de 5\% (0,05), ou seja, foi adotada a seguinte regra de decisão nos testes: rejeição da hipótese nula sempre que o valor-p associado ao teste foi menor que 0,05 .

\section{Resultados}

\section{Avaliação Histológica}

As lâminas coradas com H\&E do tecido proveniente do dia da captação (d0) e no $15^{\circ}$ dia de preservação (d15) não apresentaram alterações estruturais na camada superficial da cartilagem articular ( - Figura 4A-B). Contudo, nas amostras
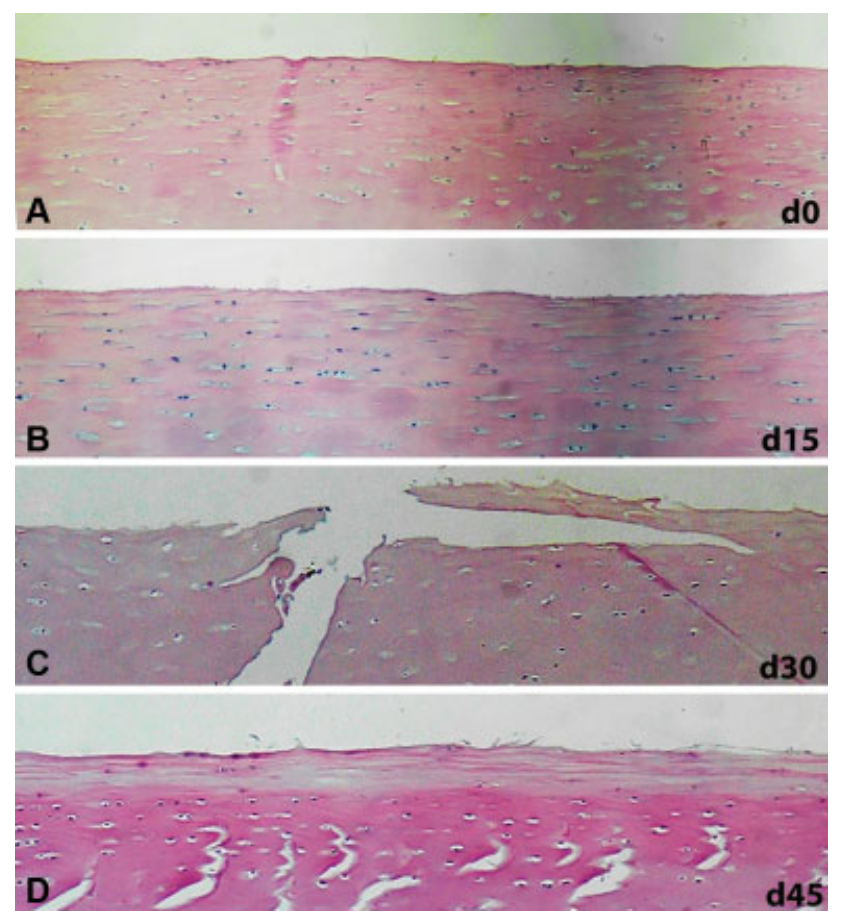

Fig. 4 Fotomicrografia da camada de cartilagem superficial preservada a $4^{\circ} \mathrm{C}$ corada com Hematoxilina e Eosina (H\&E). Cortes histológicos corados com $\mathrm{H} \& \mathrm{E}$ de fragmento osteocondral obtido no dia da captação do tecido $(A)$, corte histológico de fragmento osteocondral após 15 dias de preservação, d15 (B), corte histológico de fragmento osteocondral após 30 dias de preservação, d30 (C) e corte histológico de fragmento osteocondral após 45 dias de preservação, d45 (D). avaliadas após 30 dias (d30) e após 45 dias (d45) de preservação, foram identificadas alterações estruturais na camada superficial da cartilagem, como perda da continuidade e presença de fissuras na superfície articular (-Figura 4C-D).

Ao avaliarmos histologicamente por coloração $\mathrm{H} \& \mathrm{E}$ a região da cartilagem intermediária, não foram observadas alterações estruturais nos quatro momentos de avaliação. A camada profunda da cartilagem assim como a placa de osso subcondral, manteve-se preservada durante todo o período de preservação analisado.

A análise dos cortes histológicos corados com SO após 15 dias de preservação (d15) mostraram uma diminuição na concentração de proteoglicanos na porção periférica da camada superficial quando comparadas com as mostras em d0. Após 30 dias de preservação (d30), houve diminuição na concentração de proteoglicanos da camada superficial da cartilagem dos FO analisados. Finalmente, após 45 dias de preservação (d45) observou-se lesões estruturais difusas na camada superficial da cartilagem associadas à diminuição na concentração de proteoglicanos (-Figura 5). A análise histológica após coloração com SO não identificou diminuição na concentração de proteoglicanos na camada de cartilagem intermediária, nem na camada profunda nos quatro períodos de avaliação.
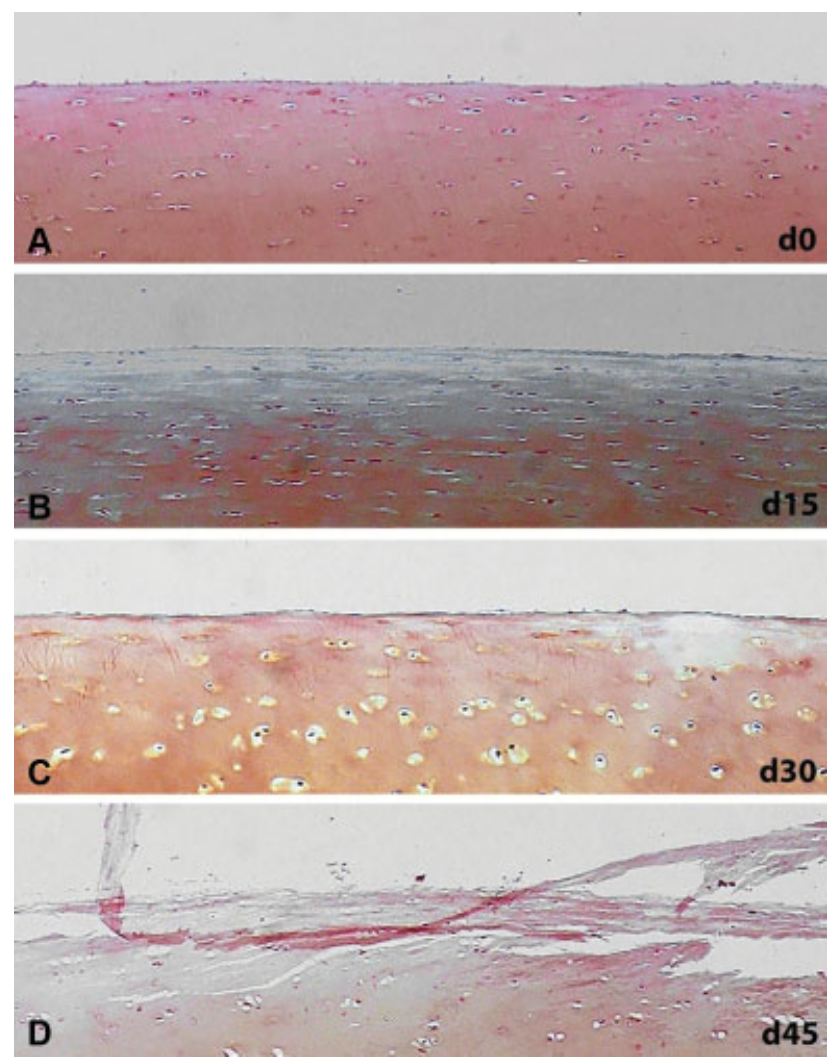

Fig. 5 Fotomicrografia da camada de cartilagem superficial preservada a $4^{\circ} \mathrm{C}$ corada com Safranina-O (SO). Corte histológico corados com SO de fragmento osteocondral obtido no dia da captação do tecido, d0 (A), corte histológico de fragmento osteocondral após 15 dias de preservação, d15 (B), corte histológico de fragmento osteocondral após 30 dias de preservação, d30 (C) e corte histológico de fragmento osteocondral após 45 dias de preservação, d45 (D). 


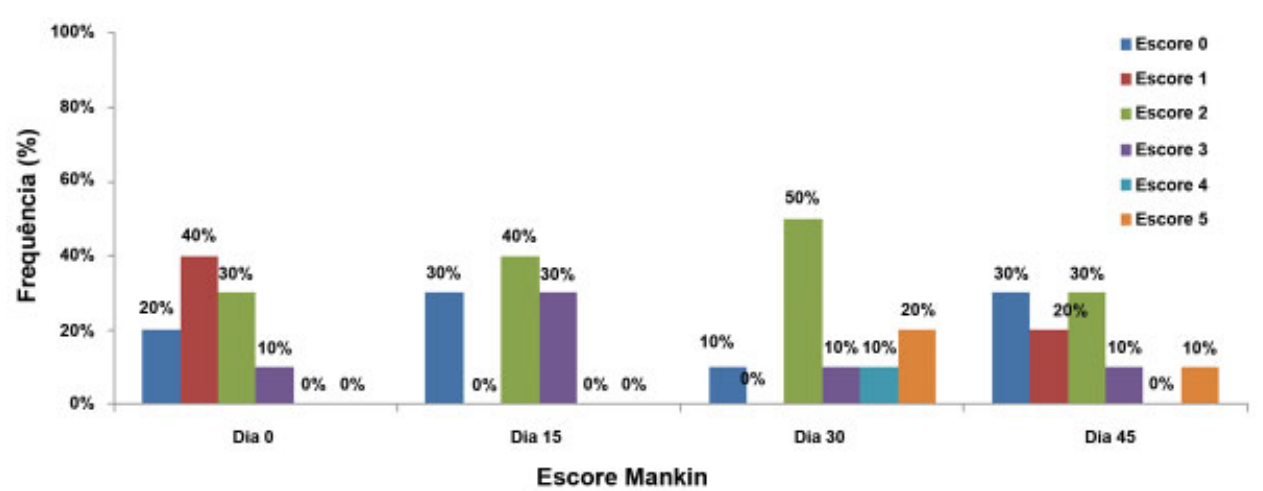

Fig. 6 Frequências dos resultados segundo o escore histológico de Mankin. A pontuação máxima obtida no escore de Mankin foi de 5 pontos.

\section{Resultado dos Escores Histológicos}

A distribuição de frequências dos resultados obtidos segundo o escore de Mankin é apresentada na - Figura 6. A maior pontuação obtida foi de cinco pontos independentemente do período analisado. Após 15 dias de preservação, 100\% das lâminas avaliadas obtiveram 3 pontos dentre os 14 pontos possíveis, demonstrando bom resultado quanto às alterações teciduais analisadas pelo escore. Após 45 dias de preservação, os resultados foram semelhantes, com $90 \%$ das lâminas avaliadas somando a pontuação até 3 .

Com 30 dias de preservação, as amostras tiveram diferença com significância estatística em relação ao tecido preservado por 15 dias, sugerindo piora na qualidade do tecido osteocondral segundo os critérios utilizados pelo escore de Mankin.

A distribuição de frequências obtidas segundo o escore da OARSI é apresentado na - Figura 7. No período definido como d0, 30\% das lâminas avaliadas apresentaram alterações histológicas mesmo antes das amostras serem submetidas à preservação a $4^{\circ} \mathrm{C}$. As alterações descritas foram restritas à camada superficial da cartilagem articular, sobretudo a diminuição da concentração de proteoglicanos. Com 15 dias de preservação, $80 \%$ das amostras foram classificadas como tipo 0 ou 1, contendo apenas alterações superficiais no tecido segundo a descrição do escore utilizado. Com 30 dias de preservação, 70\% das amostras foram classificadas como tipo 2, contendo alterações estruturais na camada superficial, assim como diminuição na concentração de proteoglicanos.
Nenhuma amostra de tecido analisada apresentou alterações relacionadas à degeneração da cartilagem articular, classificadas como tipo 4, 5 ou 6 segundo o escore da OARSI.

Segundo a avaliação histológica avaliada pelo escore da OARSI, não foram observadas variações com significância estatística entre os resultados obtidos nos diferentes períodos de avaliação do tecido osteocondral.

\section{Discussão}

O TOA representa um método biológico capaz de fornecer cartilagem hialina para o tratamento das lesões osteocondrais de espessura superior a $2 \mathrm{~cm}^{2} \cdot{ }^{1,2,4,10}$ A viabilidade celular do tecido doador no momento da cirurgia representa um fator indispensável para que haja sucesso no tratamento. A ausência de um protocolo definido na literatura nos levou à necessidade de elaborar uma metodologia própria para captação, transporte e armazenamento de tecido osteocondral humano.

Diversos fatores influenciam na preservação dos fragmentos osteocondrais humanos, visando tanto ao aumento na quantidade de condrócitos viáveis quanto ao maior período de armazenamento dos tecidos. Desta forma, a temperatura e o meio de armazenamento são variáveis muito discutidas na literatura.

Em relação à temperatura, a discussão envolve a preservação a $4^{\circ} \mathrm{C}$, a $25^{\circ} \mathrm{C}$, a $37^{\circ} \mathrm{C}$ ou a criopreservação..$^{11-17} \mathrm{O}$ aumento da temperatura de preservação está associada ao

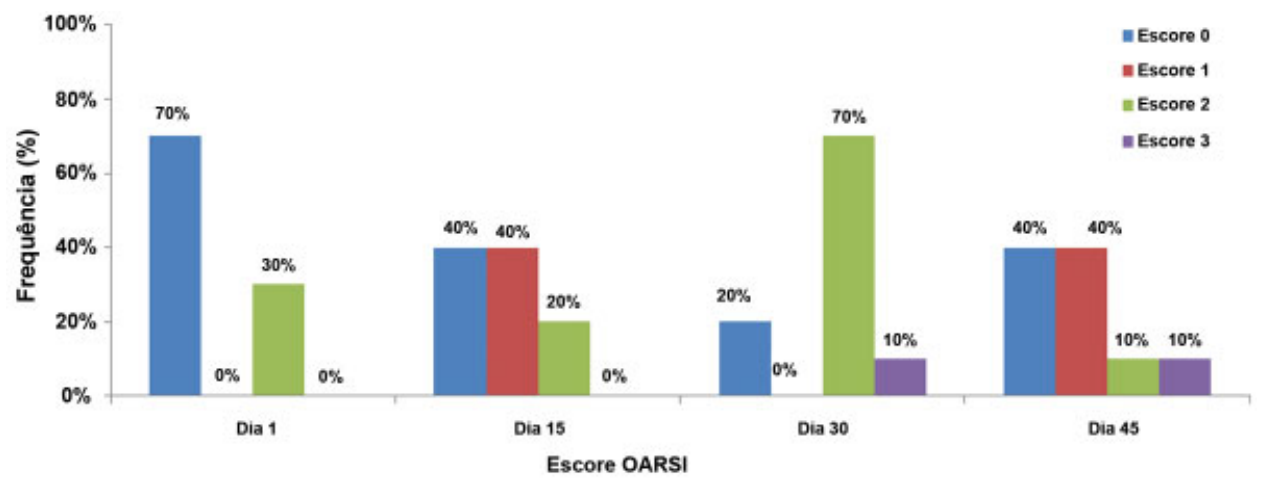

Fig. 7 Frequência de resultados obtidos através do escore da. OsteoArthritis Research Society International Abreviação: OARSI, OsteoArthritis Research Society International. 
maior consumo de nutrientes oferecidos pelo meio de preservação, havendo a necessidade da troca periódica do meio, expondo o tecido ao risco de contaminação e aumentando o custo do armazenamento. ${ }^{12}$ Cook et $\mathrm{al}^{17}$ foram capazes de comprovar até $89,8 \%$ de condrócitos viáveis em fragmentos osteocondrais caninos com a utilização do Missouri Osteochondral Allograft Preservation System (MOPS) na temperatura de $25^{\circ} \mathrm{C}$ após 60 dias de preservação tecidual; entretanto, a preservação a fresco $\left(4^{\circ} \mathrm{C}\right)$ permanece como padrão ouro na literatura.

Em estudo preliminar, realizado com material de descarte cirúrgico, nosso grupo evidenciou que a refrigeração a $4^{\circ} \mathrm{C}$ oferece melhor capacidade de preservação de fragmentos osteocondrais do que a $37^{\circ} \mathrm{C}$ por até 14 dias. ${ }^{18}$ Por esse motivo, no estudo atual, com tecidos de DCs jovens, mantivemos a opção de refrigeração dos fragmentos a $4^{\circ} \mathrm{C}$. Nossos resultados confirmam os achados anteriores que a temperatura de $4^{\circ} \mathrm{C}$ é adequada para a preservação dos aloenxertos.

Diversos meios suplementados foram avaliados quanto aos seus benefícios sobre a viabilidade do tecido cartilaginoso preservado, entre eles o meio associado a dexametasona, ${ }^{19}$ ao ácido hialurônico, ${ }^{20}$ ao soro alógeno ${ }^{21}$ ao inibidor do fator de necrose tumoral $\alpha^{19}$ e ao agente inibidor da apoptose celular, ${ }^{22}$ dentre outros. A divergência na literatura entre os meios utilizados, a ausência de pesquisas in vivo e o alto custo dos métodos de preservação avaliados dificulta a decisão quanto ao melhor suplemento a ser utilizado em conjunto com o meio de preservação para melhorar a qualidade do tecido armazenado para transplante. Pearsall et $\mathrm{al}^{7}$ determinaram que aloenxertos osteocondrais humanos poderiam ser mantidos viáveis por até 44 dias com uma viabilidade média de $67 \%$ quando mantidos em um meio de armazenamento suplementado com antibiótico, glutamina e soro fetal bovino a $10 \%$, sem fatores de crescimento. Outro estudo concluiu que os aloenxertos armazenados em solução de Ringer lactato com antibiótico poderiam ser implantados em até 7 dias, enquanto a manutenção em meio sem soro aumentaria esse prazo para 2 semanas. ${ }^{17}$ Considerando os achados desses estudos, optados em incluir no nosso protocolo o transporte dos fragmentos em Ringer lactato, por ser mais barato e acessível em qualquer hospital onde seja feita a captação de tecidos, deixando a preservação em meio Iscove's suplementado, mais cara e dependente de estrutura para preparo, para o armazenamento após o processamento pelo BT.

O método descrito para o transporte do tecido osteocondral manteve o mesmo em temperatura adequada $\left(4 / 10^{\circ} \mathrm{C}\right)$ até o início do processo de processamento tecidual. A preservação do tecido ostecondral a $4^{\circ} \mathrm{C}$ foi capaz de manter as características estruturais das camadas da cartilagem articular até 15 dias de armazenamento em meio de cultura celular sem suplementação com soro Iscove's suplementado com albumina humana a $10 \%$ e vancomicina $100 \mu \mathrm{g} / \mathrm{mL}$.

A avaliação histológica utilizando lâminas coradas em H\&E demonstrou a preservação das camadas da cartilagem articular retiradas no dia da captação do tecido (d0), sendo estas definidas como grupo controle. Após 30 e 45 dias de preservação, houve alterações na camada superficial do tecido, demonstrando que esta região está sujeita a alterações relacionadas ao tempo de preservação. A integridade da porção superficial do tecido cartilaginoso é de suma importância para a absorção e distribuição de carga. Lesões na camada de cartilagem superficial estão relacionadas a alteração na permeabilidade do tecido, favorecendo a penetração de líquido sinovial, iniciando o processo de degeneração articular. ${ }^{23}$ As camadas de cartilagem intermediária, profunda e de cartilagem calcificada não se alteraram durante 0 período avaliado. Tais achados descrevem um padrão típico de lesão relacionada à preservação de tecido osteocondral humano, no qual apenas a camada superficial da cartilagem apresentou descontinuidades e delaminações.

A avaliação visual das lâminas coradas em SO demonstrou diminuição gradual na concentração de proteoglicanos na matriz extracelular com o aumento no tempo de preservação nas amostras estudadas. Em 30\% das amostras, houve diminuição na concentração de proteoglicanos na camada superficial do tecido logo após a captação (d0). Tal achado sugere que alterações no metabolismo dos condrócitos possam existir mesmo em pacientes fisiologicamente jovens sem lesões descritas na cartilagem articular. Com 30 dias de preservação, todas as amostras analisadas apresentaram diminuição na concentração de proteoglicanos na camada superficial. As demais camadas da cartilagem articular tiveram sua concentração de proteoglicanos preservada após todo o período de avaliação (45 dias). Nossos resultados confirmam a necessidade de transplante do tecido osteocondral com menor tempo possível de preservação, pois descrevem a alteração estrutural após a preservação de FO a fresco, embora restrita à camada superficial da cartilagem articular. Alterações estruturais na camada superficial permitem o fluxo de líquido sinovial, levando à formação de cistos subcondrais, dando início ao processo de degeneração articular. $^{21}$

Nosso trabalho apresentou algumas limitações. Primeiro, não foi realizada análise quantitativa de viabilidade celular do tecido estudado. Segundo, a metodologia de avaliação histológica utilizada foi elaborada a partir de escores criados para estudo de tecido cartilaginoso com alterações degenerativas. Não há na literatura um escore histológico para avaliação de tecido osteocondral humano cadavérico. Por fim, os dados gerados são de natureza qualitativa, podendo estes estar sujeitos a variações interobservadores.

\section{Conclusão}

O protocolo descrito definiu o transporte de joelho em bloco imerso em Ringer lactato em temperatura controlada a $10^{\circ} \mathrm{C}$ até sua chegada ao banco de tecidos. Após o processamento, a solução de preservação foi composta por meio de cultura celular sem soro Iscove's suplementado com albumina humana a $10 \%$ e vancomicina $100 \mu \mathrm{g} / \mathrm{mL}$. O tecido foi preservado em temperatura a $4^{\circ} \mathrm{C}$ até o momento do transplante, caracterizando a preservação a fresco.

\section{Conflito de Interesses}

Os autores declaram não haver conflito de interesses. 


\section{Referências}

1 Zouzias IC, Bugbee WD. Osteochondral Allograft Transplantation in the Knee. Sports Med Arthrosc Rev 2016;24(02):79-84

2 Dhollander A, Verdonk P, Tirico LE, Gomoll AH. Treatment of failed cartilage repair: State of the Art. In: Journal of ISAKOS: Joint Disorders \& Orthopaedic Sports Medicine, p. jisakos. 2016000057.

3 LaPrade RF, Botker J, Herzog M, Agel J. Refrigerated osteoarticular allografts to treat articular cartilage defects of the femoral condyles. A prospective outcomes study. J Bone Joint Surg Am 2009;91(04):805-811

4 Gracitelli GC, Moraes VY, Franciozi CE, Luzo MV, Belloti JC. Surgical interventions (microfracture, drilling, mosaicplasty, and allograft transplantation) for treating isolated cartilage defects of the knee in adults. Cochrane Database Syst Rev 2016; 9:CD010675

5 De Caro F, Bisicchia S, Amendola A, Ding L. Large fresh osteochondral allografts of the knee: a systematic clinical and basic science review of the literature. Arthroscopy 2015;31(04): 757-765

6 Sherman SL, Garrity J, Bauer K, Cook J, Stannard J, Bugbee W. Fresh osteochondral allograft transplantation for the knee: current concepts. J Am Acad Orthop Surg 2014;22(02):121-133

7 Pearsall AW IV, Tucker JA, Hester RB, Heitman RJ. Chondrocyte viability in refrigerated osteochondral allografts used for transplantation within the knee. Am J Sports Med 2004;32(01): 125-131

8 Mankin HJ, Dorfman H, Lippiello L, Zarins A. Biochemical and metabolic abnormalities in articular cartilage from osteo-arthritic human hips. II. Correlation of morphology with biochemical and metabolic data. J Bone Joint Surg Am 1971;53(03):523-537

9 Pritzker KP, Gay S, Jimenez SA, et al. Osteoarthritis cartilage histopathology: grading and staging. Osteoarthritis Cartilage 2006;14(01):13-29

10 Richter DL, Schenck RC Jr, Wascher DC, Treme G. Knee articular cartilage repair and restoration techniques: a review of the literature. Sports Health 2016;8(02):153-160

11 Raz G, Safir OA, Backstein DJ, Lee PT, Gross AE. Distal Femoral Fresh Osteochondral Allografts: Follow-up at a Mean of Twentytwo Years. J Bone Joint Surg Am 2014;96(13):1101-1107
12 Williams RJ 3rd, Dreese JC, Chen CT. Chondrocyte survival and material properties of hypothermically stored cartilage: an evaluation of tissue used for osteochondral allograft transplantation. Am J Sports Med 2004;32(01):132-139

13 Ball ST, Amiel D, Williams SK, et al. The effects of storage on fresh human osteochondral allografts. Clin Orthop Relat Res 2004; (418):246-252

14 Garrity JT, Stoker AM, Sims HJ, Cook JL. Improved osteochondral allograft preservation using serum-free media at body temperature. Am J Sports Med 2012;40(11):2542-2548

15 Pallante AL, Bae WC, Chen AC, Görtz S, Bugbee WD, Sah RL. Chondrocyte viability is higher after prolonged storage at 37 degrees $C$ than at 4 degrees $C$ for osteochondral grafts. Am J Sports Med 2009;37(Suppl 1):24S-32S

16 Xia Z, Murray D, Hulley PA, Triffitt JT, Price AJ. The viability and proliferation of human chondrocytes following cryopreservation. J Bone Joint Surg Br 2008;90(09):1245-1248

17 Cook JL, Stoker AM, Stannard JP, et al. A novel system improves preservation of osteochondral allografts. Clin Orthop Relat Res 2014;472(11):3404-3414

18 de Sousa EB, Aguiar DP, Barcelos JF, Duarte ME, Olej B. Approaches to preserve human osteochondral allografts. Cell Tissue Bank 2015;16(03):425-431

19 Bian L, Stoker AM, Marberry KM, Ateshian GA, Cook JL, Hung CT. Effects of dexamethasone on the functional properties of cartilage explants during long-term culture. Am J Sports Med 2010;38(01): 78-85

20 Yamada T, Uchida K, Onuma K, et al. Hyaluronic Acid ( $800 \mathrm{kDa}$ ) Supplementation of University of Wisconsin Solution Improves Viability of Osteochondral Grafts and Reduces Matrix Metalloproteinase Expression during Cold Preservation. ScientificWorldJournal 2015;2015:631369

21 Onuma K, Urabe K, Naruse K, Uchida K, Itoman M. Allogenic serum improves cold preservation of osteochondral allografts. Clin Orthop Relat Res 2012;470(10):2905-2914

22 Linn MS, Chase DC, Healey RM, Harwood FL, Bugbee WD, Amiel D. Etanercept enhances preservation of osteochondral allograft viability. Am J Sports Med 2011;39(07):1494-1499

23 McCulloch K, Litherland GJ, Rai TS. Cellular senescence in osteoarthritis pathology. Aging Cell 2017;16(02):210-218 